PREPARED FOR THE U.S. DEPARTMENT OF ENERGY, UNDER CONTRACT DE-AC02-76CH03073

PPPL-3835

PPPL-3835

UC-70

Plasma Dielectric Tensor for Non-Maxwellian

Distributions in the FLR Limit

by

C.K. Phillips, A. Pletzer, R.J. Dumont, and D.N. Smithe

July 2003

NM|

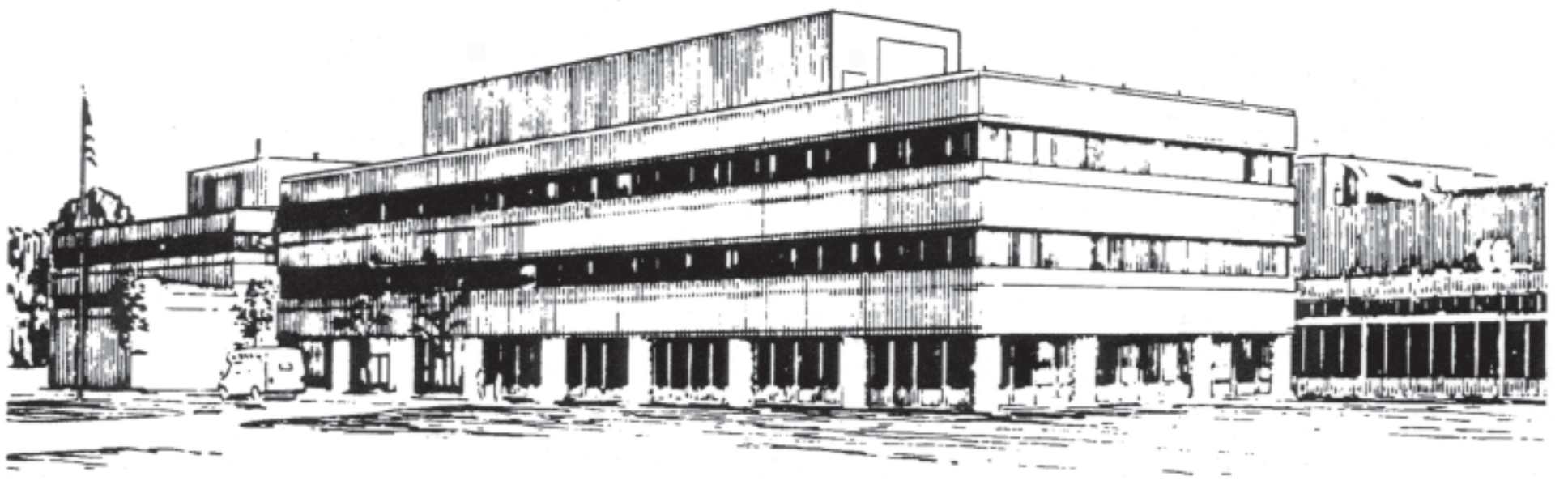

PRINCETON PLASMA PHYSICS LABORATORY PRINCETON UNIVERSITY, PRINCETON, NEW JERSEY 


\section{PPPL Reports Disclaimer}

This report was prepared as an account of work sponsored by an agency of the United States Government. Neither the United States Government nor any agency thereof, nor any of their employees, makes any warranty, express or implied, or assumes any legal liability or responsibility for the accuracy, completeness, or usefulness of any information, apparatus, product, or process disclosed, or represents that its use would not infringe privately owned rights. Reference herein to any specific commercial product, process, or service by trade name, trademark, manufacturer, or otherwise, does not necessarily constitute or imply its endorsement, recommendation, or favoring by the United States Government or any agency thereof. The views and opinions of authors expressed herein do not necessarily state or reflect those of the United States Government or any agency thereof.

\section{Availability}

This report is posted on the U.S. Department of Energy's Princeton Plasma Physics Laboratory Publications and Reports web site in Fiscal Year 2003. The home page for PPPL Reports and Publications is: http://www.pppl.gov/pub_report/

DOE and DOE Contractors can obtain copies of this report from:

U.S. Department of Energy

Office of Scientific and Technical Information

DOE Technical Information Services (DTIS)

P.O. Box 62

Oak Ridge, TN 37831

Telephone: (865) 576-8401

Fax: (865) 576-5728

Email: reports@adonis.osti.gov

This report is available to the general public from:

National Technical Information Service

U.S. Department of Commerce

5285 Port Royal Road

Springfield, VA 22161

Telephone: $1-800-553-6847$ or

(703) $605-6000$

Fax: (703) 321-8547

Internet: http://www.ntis.gov/ordering.htm 


\title{
Plasma Dielectric Tensor for Non-Maxwellian Distributions in the FLR Limit
}

\author{
C.K. Phillips ${ }^{1}$, A. Pletzer ${ }^{1}$, R.J. Dumont ${ }^{2}$ and D.N. Smithe ${ }^{3}$ \\ ${ }^{1}$ Princeton Plasma Physics Laboratory, P.O. Box 451, Princeton, NJ 08540, U.S.A. \\ ${ }^{2}$ Association Euratom-CEA sur la Fusion Contrôlée, F-13108 St Paul lez Durance, France \\ ${ }^{3}$ Mission Research Corp., Newington, VA 22122, U.S.A.
}

\begin{abstract}
Previous analytical and numerical studies have noted that the presence of fully nonMaxwellian plasma species can significantly alter the dynamics of electromagnetic waves in magnetized plasmas. In this paper, a general form for the hot plasma dielectric tensor for nonMaxwellian distributions is derived that is valid in the finite Larmor radius approximation. This model provides some insight into understanding the limitations on representing non-Maxwellian plasma species with equivalent Maxwellian components in modeling RF wave propagation and absorption.
\end{abstract}

\section{INTRODUCTION}

Laboratory fusion plasmas as well as many space plasmas can be comprised of both thermal and non-thermal species. In collisionless space plasmas, turbulent heating or shock processes can accelerate particles, resulting in velocity-space distributions that are Lorentzian or power-law-like in nature [1-3]. Neutral beam injection and fusion reactions in laboratory fusion plasmas both introduce energetic ions, which follow a slowing-down type distribution in velocity space. Finally, when electromagnetic waves are applied to heat or else to drive noninductive currents in magnetized plasmas, the wave-induced particle acceleration results in velocity-space distributions that feature energetic "tails" or extended "quasilinear plateaus". In all of these situations, the question that arises is whether or not these non-thermal plasma species have a noticeable impact on electromagnetic wave dynamics in these plasmas.

Previous analytical and numerical studies [1-6] have shown that wave dynamics can be affected if a sizeable non-thermal ion population is present in the plasma. Most of these studies have focused on modifications to wave absorption or to instability thresholds. A number of these studies [4,5,7] have noted that power absorption on a non-Maxwellian distribution can be approximated by that on an equivalent Maxwellian, chosen so that the thermal speed of the equivalent Maxwellian is equal to the velocity-space averaged perpendicular speed of the non-thermal distribution.

More recently, a 1D all-orders local full wave, METS [8], has been extended to include the effects of non-thermal species on both wave propagation and absorption. Results from this code indicate that the absorption and wave propagation in plasmas with isotropic, non-Maxwellian species can be reasonably simulated with equivalent 
Maxwellian in many regimes. However, the spatial profile of power deposition on short wavelength kinetic waves can be narrower and anisotropic effects can lead to larger discrepancies with models based on equivalent Maxwellians [8].

In this paper, the hot plasma dielectric susceptibility for a fully non-Maxwellian but still gyrotropic particle distribution function is derived that is valid in the finite Larmor radius limit (FLR). This model provides some insight into understanding the limitations on representing non-thermal species as equivalent Maxwellians in modeling RF wave absorption and propagation. It also provides the basis for generalizing the plasma dielectric operators in FLR-based 2D full wave simulation codes.

\section{DERIVATIONS}

The hot plasma susceptibility for a given species, "s", described by the gyrotropic particle velocity distribution $\mathrm{f}_{0}\left(\mathrm{v}_{\perp}, \mathrm{v}_{/ /}\right)$, in a homogeneous, uniformly magnetized plasma can be written in the following form:

$$
\begin{aligned}
\vec{\chi}_{\mathrm{s}}= & \frac{\omega_{\mathrm{ps}}^{2}}{\omega} \int_{0}^{\infty} 2 \pi \mathrm{v}_{\perp} \mathrm{dv} \perp \int_{-\infty}^{\infty} \mathrm{dv} / / \hat{\mathrm{z}} \hat{\mathrm{z}} \frac{\mathrm{v}^{2} / /}{\omega}\left(\frac{1}{\mathrm{v} / /} \frac{\partial \mathrm{f}_{0}}{\partial \mathrm{v} / /}-\frac{1}{\mathrm{v}_{\perp}} \frac{\partial \mathrm{f}_{0}}{\partial \mathrm{v}_{\perp}}\right)_{\mathrm{s}}+ \\
& \frac{\omega_{\mathrm{ps}}^{2}}{\omega} \int_{0}^{\infty} 2 \pi \mathrm{v}_{\perp} \mathrm{dv} \perp \int_{-\infty}^{\infty} \mathrm{dv} / / \sum_{\mathrm{n}=-\infty}^{\mathrm{n}=\infty}\left[\frac{\mathrm{v} \perp \mathrm{U}}{\omega-\mathrm{k} / / \mathrm{v} / /-\mathrm{n} \Omega} \overrightarrow{\mathrm{T}}_{\mathrm{n}}\right]_{\mathrm{s}},
\end{aligned}
$$

where $\vec{T}_{\mathrm{n}}$ is given in Equation (10-48) of reference [9] by Stix. In the FLR limit, the expressions in Equation (1) may be simplified by replacing the Bessel functions in $\overrightarrow{\mathrm{T}}_{\mathrm{n}}$ by their series expansions, integrating by parts the terms involving $\int_{0}^{\infty} 2 \pi \mathrm{v}_{\perp} \mathrm{dv}_{\perp}\left(\mathrm{v}_{\perp}^{\mathrm{m}}\right) \partial \mathrm{f}_{0} / \partial \mathrm{v} \perp(\ldots \ldots$.$) , and retaining terms through order \lambda \sim \mathrm{k}_{\perp}^{2} \mathrm{w}_{\perp}^{2} / 2 \Omega_{\mathrm{S}}^{2}$,

where $\Omega_{\mathrm{s}}$ is the cyclotron frequency and $\mathrm{w}_{\perp}^{2}$ is the velocity space average of the perpendicular velocity. The resulting form of the plasma susceptibility is a generalization of the Maxwellian-based FLR susceptibility given by Stix in Equations (59-63) in Chapter 10 in reference [9]. It may be written in similar but generalized form as:

$$
\begin{aligned}
& \chi_{x x}=\frac{\omega_{\mathrm{p}}^{2}}{\omega}\left\{\frac{1}{2}\left[\tilde{\mathrm{A}}_{1,0}+\tilde{\mathrm{A}}_{-1,0}\right] \frac{\lambda}{2}\left[\tilde{\mathrm{A}}_{1,1}+\tilde{\mathrm{A}}_{-1,1}\right]+\frac{\lambda}{2}\left[\tilde{\mathrm{A}}_{2,1}+\tilde{\mathrm{A}}_{-2,1}\right]\right\} \\
& \chi_{\mathrm{xy}}=\mathrm{i} \frac{\omega_{\mathrm{p}}^{2}}{\omega}\left\{\frac{1}{2}\left[\tilde{\mathrm{A}}_{1,0}-\tilde{\mathrm{A}}_{-1,0}\right]-\lambda\left[\tilde{\mathrm{A}}_{1,1}-\tilde{\mathrm{A}}_{-1,1}\right]+\frac{\lambda}{2}\left[\tilde{\mathrm{A}}_{2,1}-\tilde{\mathrm{A}}_{-2,1}\right]\right\}
\end{aligned}
$$




$$
\begin{aligned}
& \chi_{\mathrm{xz}}=\frac{\omega_{\mathrm{p}}^{2}}{\omega}\left(\frac{1}{2} \frac{\mathrm{k} \perp}{\Omega}\right)\left\{\left[\tilde{\mathrm{B}}_{1,0}+\tilde{\mathrm{B}}_{-1,0}\right]-\lambda\left[\tilde{\mathrm{B}}_{1,1}+\tilde{\mathrm{B}}_{-1,1}\right]+\frac{\lambda}{2}\left[\tilde{\mathrm{B}}_{2,1}+\tilde{\mathrm{B}}_{-2,1}\right]\right\} \\
& \chi_{\text {yy }}=\frac{\omega_{\mathrm{p}}^{2}}{\omega}\left\{2 \lambda \tilde{\mathrm{A}}_{0,1}+\frac{1}{2}\left[\tilde{\mathrm{A}}_{1,0}+\tilde{\mathrm{A}}_{-1,0}\right]-\frac{3 \lambda}{2}\left[\tilde{\mathrm{A}}_{1,1}+\tilde{\mathrm{A}}_{-1,1}\right]+\frac{\lambda}{2}\left[\tilde{\mathrm{A}}_{2,1}+\tilde{\mathrm{A}}_{-2,1}\right]\right\} \\
& \chi_{\mathrm{yz}}=\mathrm{i} \frac{\omega_{\mathrm{p}}^{2}}{\omega}\left(\frac{\mathrm{k} \perp}{\Omega}\right)\left\{\tilde{\mathrm{B}}_{0,0}-\lambda \tilde{\mathrm{B}}_{0,1}-\frac{1}{2}\left[\tilde{\mathrm{B}}_{1,0}+\tilde{\mathrm{B}}_{-1,0}\right]\right. \\
& \left.-\lambda\left[\tilde{\mathrm{B}}_{1,1}+\tilde{\mathrm{B}}_{-1,1}\right]-\frac{\lambda}{4}\left[\tilde{\mathrm{B}}_{2,1}+\tilde{\mathrm{B}}_{-2,1}\right]\right\} \\
& \chi_{\mathrm{zz}}=\frac{2 \omega_{\mathrm{p}}^{2}}{\omega \mathrm{k} / / \mathrm{w}_{\perp}^{2}} \int_{-\infty}^{\infty} \mathrm{dv} / / \int_{0}^{\infty} 2 \pi \mathrm{v}_{\perp} \mathrm{dv} \perp \mathrm{v} / /\left[\frac{-1}{\mathrm{v}_{\perp}} \frac{\partial \mathrm{f}_{0}}{\partial \mathrm{v}_{\perp}} \frac{\mathrm{w}_{\perp}^{2}}{2}\right\rfloor \\
& +\frac{\omega_{\mathrm{p}}^{2}}{\omega}\left[\frac{2 \omega}{\mathrm{k}_{/ / \mathrm{w}_{\perp}^{2}}}\right]\left\{(1-\lambda) \tilde{\mathrm{B}}_{0,0}\right. \\
& \left.+\int_{-\infty}^{\infty} \mathrm{dv} / / \int_{0}^{\infty} 2 \pi \mathrm{v} \perp \mathrm{dv} \perp \frac{\mathrm{v} / /}{\omega-\mathrm{k} / / \mathrm{v} / /}\left[\frac{1}{2} \frac{\mathrm{w}_{\perp}^{2}}{\mathrm{v} \perp} \frac{\partial \mathrm{f}_{0}}{\partial \mathrm{v}_{\perp}}+\mathrm{f}_{0}\right]\left(\frac{1-\mathrm{k} / / \mathrm{v} / /}{\omega}\right)\right\} \\
& +\frac{1}{2} \frac{\omega_{\mathrm{p}}^{2}}{\omega} \lambda\left\{\frac{2(\omega-\Omega)}{{\mathrm{k} / / \mathrm{w}_{\perp}^{2}}^{2}} \tilde{\mathrm{B}}_{1,0}+\frac{2(\omega+\Omega)}{{\mathrm{k} / / \mathrm{w}_{\perp}^{2}}_{\perp}} \tilde{\mathrm{B}}_{-1,0}\right\}
\end{aligned}
$$

where, for $\mathrm{j}=0,1$ :

$$
\begin{gathered}
\tilde{\mathrm{A}}_{\mathrm{n}, \mathrm{j}}=\int_{-\infty}^{\infty} \mathrm{dv} / / \frac{1}{\omega-\mathrm{k} / / \mathrm{v} / /-\mathrm{n} \Omega} \int_{0}^{\infty} 2 \pi \mathrm{v}_{\perp} \mathrm{dv} \mathrm{v}_{\perp} \mathrm{Hj}\left(\mathrm{v} / /, \mathrm{v}_{\perp}\right) \\
\tilde{\mathrm{B}}_{\mathrm{n}, \mathrm{j}}=\int_{-\infty}^{\infty} \mathrm{dv} / / \frac{\mathrm{v} / /}{\omega-\mathrm{k} / / \mathrm{v} / /-\mathrm{n} \Omega} \int_{0}^{\infty} 2 \pi \mathrm{v}_{\perp} \mathrm{dv} \mathrm{v}_{\perp} \mathrm{Hj}\left(\mathrm{v} / /, \mathrm{v}_{\perp}\right) \\
\mathrm{H}_{0}(\mathrm{v} / /, \mathrm{v} \perp)=\frac{1}{2} \frac{\mathrm{k} / / \mathrm{w}_{\perp}^{2}}{\omega} \frac{\partial \mathrm{f}_{0}}{\partial \mathrm{v} / /}-\left(1-\frac{\mathrm{k} / / \mathrm{v}_{/ /}}{\omega}\right) \mathrm{f}_{0}\left(\mathrm{v} / /, \mathrm{v}_{\perp}\right) \\
\mathrm{H}_{1}\left(\mathrm{v} / /, \mathrm{v}_{\perp}\right)=\frac{1}{2} \frac{\mathrm{k}_{/ / \mathrm{w}_{\perp}}^{2} \frac{\partial \mathrm{f}_{0}}{\partial \mathrm{v}_{\perp}} \frac{4}{4}-\left(1-\frac{\mathrm{k} / / \mathrm{v} / /}{\omega}\right) \mathrm{f}_{0}\left(\mathrm{v}_{\perp} /, \mathrm{v}_{\perp}\right) \frac{\mathrm{v}_{\perp}^{2}}{\mathrm{w}_{\perp}^{2}}}{}
\end{gathered}
$$

In the limit that $f_{0}\left(v_{\perp}, v_{/ /}\right)=f_{\max }\left(v_{\perp}\right) h\left(v_{/ /}\right)$, then the generalized susceptibility reduces to that given in reference [9]. 


\section{DISCUSSION}

The local hot plasma susceptibility for a given species, "s", described by the gyrotropic particle velocity distribution $\mathrm{f}_{0}\left(\mathrm{v}_{\perp}, \mathrm{V}_{/}\right)$, that is valid in the FLR approximation has been derived by expanding the full hot plasma susceptibility to first order in $\lambda \sim \mathrm{k}_{\perp}^{2} \mathrm{w}_{\perp}^{2} / 2 \Omega_{\mathrm{S}}^{2}$. In the limit that $\mathrm{k}_{/ /} \Rightarrow 0$, the FLR-based susceptibility for a general distribution differs from that of a Maxwellian distribution only in terms of $\mathrm{O}(\lambda)$. The $\mathrm{xx}$, xy, and yy elements will be the same as that of an equivalent Maxwellian in this limit, provided that the thermal speed of the Maxwellian is chosen to equal $w_{\perp}^{2}$. Hence, the propagation of waves, such as fast waves or ion Bernstein waves, which depends on these elements, can be simulated exactly using the equivalent Maxwellian. The $\chi_{\mathrm{xz}}$ and $\chi_{\mathrm{yz}}$ elements will be approximately equal in this limit, provided the ratio:

$$
\frac{\mathrm{I}_{\mathrm{v}}}{\langle\mathrm{v} / /\rangle}=\frac{\int_{0}^{\infty} 2 \pi \mathrm{v}_{\perp} \mathrm{dv} \perp \int_{-\infty}^{\infty} \mathrm{dv} / / \mathrm{v} / / \mathrm{f}_{0}\left(\mathrm{v}_{/}, \mathrm{v}_{\perp}\right) \frac{\mathrm{v}_{\perp}^{2}}{\mathrm{w}_{\perp}^{2}}}{\int_{0}^{\infty} 2 \pi \mathrm{v}_{\perp} \mathrm{dv} \perp \int_{-\infty}^{\infty} \mathrm{d} \mathrm{v} / / \mathrm{v} / / \mathrm{f}_{0}\left(\mathrm{v} / /, \mathrm{v}_{\perp}\right)}
$$

is close to unity. More generally, the FLR-based susceptibility elements for a general, gyrotropic distribution can be computed using equivalent Maxwellians, if the (velocity $)^{\mathrm{n}}$ moments for the general distribution are similar to those of the equivalent Maxwellian. Finally, the expressions for the FLR-based susceptibility given in Equations (2)-(11) may be utilized to generalize the dielectric operator in 2D FLRbased full wave codes. Such a generalization is required in order to self-consistently integrate such codes with Fokker-Planck packages.

\section{ACKNOWLEDGMENTS}

This work was supported by U.S.D.O.E. contract DE-AC02-76CH03073.

\section{REFERENCES}

1. Gedalin, M., Lyubarsky, Y., Balikhin, M. and Russell, C.T., Phys. Plasmas 8, 2934 (2001).

2. Gedalin, M., Strangeway, R.J., and Russell, C.T., J. Geophys. Res. 107, SSH 1-1,6 (2002).

3. Heilberg, M. and Mace, R.L., Phys. Plasmas 9, 1495 (2002).

4. Koch, R. Phys. Letts. A 157, 399 (1991).

5. Van Eester, D., Plasma Phys. Controlled Fusion 35, 441-451 (1993).

6. Batchelor, D.B., Jaeger, E.F., and Colestock, P.L., Phys. Fluids B1, 1174 (1989).

7. Sauter, O. and Vaclavik, J., Nucl. Fusion 32, 1455 (1992).

8. Dumont, R.J., Phillips, C.K., and Smithe, D.N., "Effects of non-Maxwellian Plasma Species on ICRF Propagation and Absorption in Toroidal Magnetic Confinement Devices," this conference.

9. Stix, T.H., "Susceptibilities for a Hot Plasma in a Magnetic Field," in Waves in Plasmas, New York: American Institute of Physics, 1992, pp. 237-264. 


\section{External Distribution}

Plasma Research Laboratory, Australian National University, Australia

Professor I.R. Jones, Flinders University, Australia

Professor João Canalle, Instituto de Fisica DEQ/IF - UERJ, Brazil

Mr. Gerson O. Ludwig, Instituto Nacional de Pesquisas, Brazil

Dr. P.H. Sakanaka, Instituto Fisica, Brazil

The Librarian, Culham Laboratory, England

Mrs. S.A. Hutchinson, JET Library, England

Professor M.N. Bussac, Ecole Polytechnique, France

Librarian, Max-Planck-Institut für Plasmaphysik, Germany

Jolan Moldvai, Reports Library, Hungarian Academy of Sciences, Central Research Institute for Physics, Hungary

Dr. P. Kaw, Institute for Plasma Research, India

Ms. P.J. Pathak, Librarian, Institute for Plasma Research, India

Ms. Clelia De Palo, Associazione EURATOM-ENEA, Italy

Dr. G. Grosso, Instituto di Fisica del Plasma, Italy

Librarian, Naka Fusion Research Establishment, JAERI, Japan

Library, Laboratory for Complex Energy Processes, Institute for Advanced Study, Kyoto University, Japan

Research Information Center, National Institute for Fusion Science, Japan

Dr. O. Mitarai, Kyushu Tokai University, Japan

Dr. Jiangang Li, Institute of Plasma Physics, Chinese Academy of Sciences, People's Republic of China

Professor Yuping Huo, School of Physical Science and Technology, People's Republic of China

Library, Academia Sinica, Institute of Plasma Physics, People's Republic of China

Librarian, Institute of Physics, Chinese Academy of Sciences, People's Republic of China

Dr. S. Mirnov, TRINITI, Troitsk, Russian Federation, Russia

Dr. V.S. Strelkov, Kurchatov Institute, Russian Federation, Russia

Professor Peter Lukac, Katedra Fyziky Plazmy MFF UK, Mlynska dolina F-2, Komenskeho Univerzita, SK-842 15 Bratislava, Slovakia

Dr. G.S. Lee, Korea Basic Science Institute, South Korea

Institute for Plasma Research, University of Maryland, USA

Librarian, Fusion Energy Division, Oak Ridge National Laboratory, USA

Librarian, Institute of Fusion Studies, University of Texas, USA

Librarian, Magnetic Fusion Program, Lawrence Livermore National Laboratory, USA

Library, General Atomics, USA

Plasma Physics Group, Fusion Energy Research Program, University of California at San Diego, USA

Plasma Physics Library, Columbia University, USA

Alkesh Punjabi, Center for Fusion Research and Training, Hampton University, USA

Dr. W.M. Stacey, Fusion Research Center, Georgia Institute of Technology, USA

Dr. John Willis, U.S. Department of Energy, Office of Fusion Energy Sciences, USA

Mr. Paul H. Wright, Indianapolis, Indiana, USA 
The Princeton Plasma Physics Laboratory is operated by Princeton University under contract with the U.S. Department of Energy.

\author{
Information Services \\ Princeton Plasma Physics Laboratory \\ P.O. Box 451 \\ Princeton, NJ 08543
}

Phone: 609-243-2750

Fax: 609-243-2751

e-mail: pppl_info@pppl.gov

Internet Address: http://www.pppl.gov 